\title{
O GÊNERO NEUTRO NO REGISTRO CIVIL DAS PESSOAS NATURAIS.
}

\author{
Lorruane Matuszewski ${ }^{1}$ \\ Ricardo Henrique Alvarenga Cunha ${ }^{2}$ \\ Rodrigo Rodrigues Correia ${ }^{3}$
}

Resumo: O artigo trata da autodeterminação do gênero "neutro" e suas repercussões no registro civil. Foi empregado o método científico dedutivo, partindo-se dos princípios relacionados, para alcançar a dedução particular, comparando com as soluções presente nas decisões judiciais e no regulamento do CNJ. Como resultado, são apresentados, os fundamentos do direito ao nome e os efeitos na identificação das pessoas transgêneras, a adaptação do registro civil após a ADI n 4.275/DF e o Provimento n 73/2018 do CNJ, bem como a extensão desta solução àqueles que se identificam como o gênero neutro.

Palavras-chave: Autodeterminação de gênero; Transgênero; Intersexuais; Gênero neutro; Registro Civil das Pessoas Naturais.

\section{GENDER NEUTRAL IN THE CIVIL REGISTRY}

Abstract: The article deals with the self-determination of the "neutral" genre and its repercussions on the civil registry. The deductive scientific method was used, based on the related principles, to achieve the particular deduction, comparing with the solutions present in the judicial decisions and in the $\mathrm{CNJ}$ regulations. As a result, the fundamentals of the right to name and the effects on the identification of transgender people are presented, the adaptation of the civil registry after ADI $n^{\circ} 4.275$ / DF and Provimento $n^{\circ} 73 / 2018$ of the CNJ, as well as the extension of this solution to gender neutral.

Keywords: Gender self-determination; Transgender; Intersex; Gender neutral; Civil registry

\section{Introdução.}

O presente artigo tem por objetivo discorrer a acerca da autodeterminação do gênero e os seus efeitos no procedimento de alteração do nome e do gênero das pessoas transgêneras, bem como das agêneras, perante o Registro Civil das Pessoas Naturais.

\footnotetext{
*Doutoranda em Direito na FADISP. Mestre em Direito na UNIMAR. Pós-graduada em Direito Notarial e Registral. Registradora de Imóveis no Estado de São Paulo. Endereço: Rua Dr. Geraldo Coelho, 148, Palmital/SP E-mail: lorruane@gmail.com

** Doutorando em Direito na FADISP. Mestre em Direito na FADISP. Pós-graduado em Direito Notarial e Registral na PUC/SP. Registrador de Imóveis no Paraná.Endereço: Avenida Prefeito Daniel Jorge, 420, Sengés/PR E-mail: ricardohac@gmail.com

*** Doutorando em Direito na FADISP. Mestre em Direito na FADISP. Pós-graduado em Direito Notarial e Registral pela EPM. Registrador de Imóveis em São Paulo. Endereço: Avenida Newton Prado, 2796, Pirassununga/SP E-mail: rodrigo.r.correia@gmail.com
} 
O problema central a ser debatido é: pode a pessoa intersexual se valer do mesmo procedimento destinado aos transexuais, para a mudança do nome e sexo no registro civil, a fim de alterar a informação do sexo no registro para um terceiro gênero?

O metodologia adotada no artigo é o método científico dedutivo, partindo-se dos princípios relacionados ao problema, para alcançar a dedução particular, comparando com as presentes nas recentes decisões judiciais a respeito, e nos regulamentos do Conselho Nacional de Justiça que tentam desjudicializar soluções, como forma de reduzir o tratamento discriminatório recebido pelas pessoas que intimamente não se consideram pertencente ao gênero que lhe foi atribuído ao nascer, ou não se encaixam na identidade de gênero binária masculino e feminino.

A exposição do estudo é dividida em três partes, tratando preliminarmente dos fundamentos do direito ao nome, a sexualidade e os efeitos de sua adequação na identificação das pessoas transgêneras perante a coletividade. Na sequência se analisa a alteração do nome e do gênero nos registros públicos pelos transexuais e intersexuais, após a decisão do STF na Ação Direta de Inconstitucionalidade 4.275/DF e o Provimento $n^{\circ} 73 / 2018$ do Conselho Nacional de Justiça. Por fim, aborda a autodeterminação do gênero e o reconhecimento do gênero "neutro" na jurisprudência, especialmente na mudança de prenome e de gênero pelos intersexuais e a segurança jurídica esperada dos registros públicos.

\section{O debate jurídico da identidade de gênero e sua adequação nos registros públicos}

Tema de grande relevância atual, a identidade de gênero provoca discussões em vários setores da sociedade, trazendo reflexões sobre o humano e sua compreensão numa sociedade plural e diversificada. A sexualidade em todas suas formas, demandou adequações no tratamento jurídico conferido aos grupos minoritários, tais como os transgêneros, com debates a respeito das causas, consequências e soluções para os problemas enfrentados (BERKMAN, 2013).

A identidade do ser humano é formada por vários elementos e, sem dúvida, o nome e o sexo são de extrema relevância para a forma como são conhecidas na sociedade, pelo modo como se identificam e querem ser identificadas. Todavia, o próprio conceito de homem e mulher sofreu mudanças e a identidade de gênero, masculino/feminino, por vezes deixa de fora outras formas existentes de reconhecimento das pessoas. 
A sexualidade é um aspecto central do ser humano, integrante da personalidade de cada um, sendo constituída pelo sexo, pelo gênero, pela identidade de gênero, pela orientação sexual, pelo erotismo, pelo prazer, pela intimidade e pela reprodução, dentre outros componentes, de acordo com a Organização Mundial da Saúde (OMS). Estudos sobre o tema apontam que a sexualidade é construída socialmente pela soma das realidades individual, cultural e histórica do seu titular, manifestando-se de diferentes modos (CARDIN, 2016).

Ordinariamente na medicina, a definição do sexo de um indivíduo é determinado por diferentes fatores biológicos e psicológicos, sendo que o sexo biológico resulta de fatores genéticos (depende da constituição cromossômica e é imutável) e endócrinos (resulta de condições hormonais) que derivam o sexo morfológico da pessoa, e o sexo psicológico é revelado pelo comportamento do indivíduo e decorre de fatores biológicos e ambientais (SUTTER, 1993).

A determinação jurídica do sexo no Brasil ocorre no momento do nascimento da pessoa, sendo verificada apenas a formação dos órgãos sexuais, devendo o médico responsável pelo parto, ao preencher a Declaração de Nascido Vivo (DNV), assinalar uma das seguintes opções: masculino, feminino e ignorado, sendo que esta última opção somente pode ser marcada em caso de genitália indefinida ou hermafroditismo. Portanto, o sexo que é objeto do registro público do recém-nascido, leva em consideração, unicamente, o critério biológico para sua definição (CASTRO, 2018).

O gênero é tratado por como uma construção social que atribuí uma série de atributos para diferenciar homens e mulheres em razão de seu sexo biológico, estando, portanto, a identidade de gênero ligada em como a pessoa se reconhece: como homem, como mulher, como ambos ou como nenhum, independe dos órgãos genitais e de qualquer outra característica anatômica (DIAS, 2014).

A identidade de gênero não deve ser confundida com a orientação sexual, que está diretamente relacionada à atração sexual. Se atraída por pessoa de gênero oposto diz-se heterossexual; do mesmo, homossexual; e por ambos, bissexual.

O termo cisgênero refere-se as pessoas que tem identidade de gênero compatível com o gênero ao qual foi atribuído ao nascer da Declaração de Nascido Vivo e refletido nos assentos registrais no campo "sexo", masculino ou feminino. 
O termo transgênero, por sua vez, refere-se às pessoas que não se identificam com o gênero constante em seu nascimento, podendo preferir serem tratadas no feminino ou no masculino (trans) ou, ainda, não se encaixar em nenhuma dessas definições (trans não binárias). É comum que estes indivíduos, que desde tenra idade, não aceitem o seu gênero, sintam-se em desconexão psíquico-emocional com o seu sexo biológico, e, de um modo geral, buscam todas as formas de adequar-se ao seu sexo psicológico.

O Conselho Federal de Medicina, em norma técnica, Resolução CFM $\mathrm{n}^{\circ}$ 1.955/2.010, definiu o paciente transexual como aquele portador de desvio psicológico constante de identidade sexual, com rejeição do fenótipo e tendência à automutilação e/ou autoextermínio, devendo ser observados ainda, os seguintes critérios: desconforto com o sexo anatômico natural; desejo expresso de eliminar os genitais, perder as características primárias e secundárias do próprio sexo e ganhar as do sexo oposto; permanência desses distúrbios de forma contínua e consistente por, no mínimo, dois anos; e ausência de transtornos mentais.

Já os intersexuais são conhecidos como hermafroditas ou andrógenos e são pessoas que possuem genitais ambíguos, com características de ambos os sexos, e que podem se reconhecer como homens ou como mulher, ou nenhum deles, independente de característica física.

Estas pessoas, rotineiramente, enfrentam diversas dificuldades de convivência decorrentes da inadequação de seu gênero. Encaram adversidades de aceitação no âmbito familiar e social, além de questões de ordem psicológica e moral, decorrentes de sua frustração com seu sexo biológico.

O julgamento da ADPF no 600 em agosto de 2020, demonstra a importância do reconhecimento jurídico da identidade de gênero contra injustas discriminações, inclusive por parte do Estado, atentatórias à autonomia e respeito destas pessoas. No caso, foi julgada inconstitucional, Emenda à Lei Orgânica no 55, de 14 de setembro de 2018, do município de Londrina-PR, que vedava o ensino sobre o gênero, bem como a adoção do conceito nas escolas.

No acórdão, o Plenário do Supremo Tribunal Federal teve a oportunidade de se pronunciar sobre os conceitos de sexo, gênero e orientação sexual, utilizando como premissas 
para reconhecer o papel da educação na redução da desinformação e discriminação de transsexuais.

A identidade sexual é um direito da personalidade, vez que tutela o sentimento que a pessoa tem de pertencer a um sexo, independentemente da determinação de sua genitália (VIEIRA, 2004).

E o direito a identidade de gênero está diretamente relacionado ao direito ao nome. Isso porque, na maioria das vezes, o próprio nome permite a identificação do gênero. São, portanto, interdependentes.

A possibilidade de alteração do nome dos transsexuais, para adoção de outro que melhor corresponda ao gênero com o que a pessoa se identifica, seria uma decorrência lógica, do direito à identidade sexual em interação com o direito ao nome.

Ocorre que as hipóteses de alteração do nome são tratadas pelo Código Civil e pela Lei dos Registros Públicos como excepcionais, dentre as quais deveria estar prevista, a alteração do nome dos transsexuais e pessoas de gênero neutro, diretamente perante o Registro Civil, sem a necessidade de demanda judicial.

O Registro Civil das Pessoas Naturais faz parte de um sistema organizado para dar publicidade a situações jurídicas relativas ao estado individual e familiar da pessoa humana, constituindo prova dos fatos ou ato jurídicos inscritíveis (nascimento, casamento, óbito, interdição, emancipação) objeto do registro, minimizando incertezas pela publicidade e fé pública.

As funções do Registro Civil das Pessoas Naturais fazem dele o ofício da cidadania por excelência (art. 29, $\S 3^{\circ}$ da Lei $n^{\circ} 6.015$ de 1973), uma vez que registro de nascimento individualiza e identifica a pessoa natural na sociedade e sem ele o cidadão não obtém os demais documentos, tais como carteira de identidade, carteira de trabalho, título de eleitor, entres outros, necessários para o pleno exercício da cidadania. Ao mesmo tempo, trata-se da principal fonte de informação do Estado para a elaboração de políticas públicas em diversas áreas e referência estatística.

A pessoa natural capaz de titularizar direitos e obrigações é individualizada no ordenamento jurídico a partir de três elementos essenciais: nome, domicílio e estado. A 
maioria dessas qualidades do sujeito estão presentes no registro de nascimento, como nome, naturalidade, idade, sexo e parentesco.

Faz poucos anos que transgêneros conquistaram o reconhecimento do direito de adequação de seu gênero nos registros públicos, ainda na esfera infralegal, mas que permite a alteração de seu nome e sexo para aquele com o qual se identifica.

A corrente doutrinária defensora da impossibilidade de mudança do nome e sexo argumentava que os fatores biológicos, tais como o sexo real cromossômico, gonádico e fenotípico, devam prevalecer sobre a vontade psíquica do indivíduo. Outro argumento é de que induziria em erro aquele que viesse a relacionar-se com a referida pessoa, sem a possibilidade de procriar. Há posições que defendem a publicização do termo transexual na certidão do nascimento a fim de proteger terceiros de serem induzidos em erro (DINIZ, 2006).

Já a corrente acolhedora da alteração do registro civil interpreta o ser humano em sua integridade física, psicológica, socioambiental e ético-espiritual, de forma a não fechar os olhos para a realidade da aparência e comportamento da pessoa, evitando conflitos, angústia e incertezas em sua vida.

O texto constitucional passou a ser o centro axiológico do ordenamento jurídico, sendo dignidade humana o fundamento do Estado Democrático de Direito, o que gerou reflexos no princípio da imutabilidade do nome com o advento da Lei no 9.708 de 1998 que alterou a redação do artigo 58 da Lei de Registros Públicos, permitindo alterações.

Passaram a ser admitidos, a sua substituição do prenome por apelidos públicos notórios, bem como nas hipóteses de fundada coação ou ameaça decorrente da colaboração com a apuração de crime.

Todavia, relações sociais até pouco tempo invisíveis aos olhos do poder público, fizeram com que a jurisprudência abarcasse hipóteses não previstas na legislação, permitindo o acesso de novos fatos e atos jurídicos nos assentos registrais, como o reconhecimento e autorização de casamento homoafetivos. Decisões recentes vão no sentido da necessidade de se fazer constar no assento de nascimento, no campo relativo ao sexo, a informação "não especificado" de um terceiro gênero "neutro", "indefinido" ou "não definido". 
A compreensão da autonomia privada no início do século XXI engloba a autodeterminação para as situações subjetivas existenciais, trazendo consigo a responsabilidade em contrapartida, pois a pessoa precisa ter discernimento para tomar as decisões autorreferentes a estar ciente das consequências de seus atos (BUCCAR, 2016).

\section{3. $O$ impacto da ADI $n^{\circ}$ 4.275/DF e o Provimento $n^{0} 73$ do CNJ}

A ausência de legislação sobre a possibilidade de mudança de nome e sexo no assento de nascimento decorrentes da situação jurídica dos transgêneros encontrou guarida no Poder Judiciário, que se manifestou por diversas vezes em relação ao tema.

É possível notar três fases na jurisprudência nacional relativa à mudança de nome e sexo dos transgêneros. Na primeira fase não eram autorizadas as mudanças de nome e sexo dos transexuais, mesmo dos que haviam se submetido a cirurgia de redesignação sexual.

Os argumentos utilizados eram de que tal operação não era admitida no Brasil, sendo portanto ilícita, e ela não tinha o condão de transformar o estado da pessoa; que não havia legislação autorizando tal mudança e prevalecia o princípio da imutabilidade do nome; e também se utilizavam de fundamentos relativos às consequências desta mudança, como os relativos ao casamento, uma vez que a legislação brasileira exige a diversidade de gênero para tal, e poderia ocasionar o erro quanto a pessoa, causa de anulação do casamento. Os julgados do Tribunal de Justiça do Estado do Rio de Janeiro, Apelação nº 00056440319928190000, e do Tribunal de Justiça do Estado do Paraná, Apelação Cível no 0030019-8, são exemplos desse entendimento.

Já na segunda fase, passou-se a permitir a alteração do nome e do sexo, desde que fosse dada publicidade a esta alteração no registro público e a pessoa tivesse se submetido ao procedimento cirúrgico de redesignação sexual. Os julgadores defendiam a publicidade da alteração para garantir a segurança jurídica evitando-se assim questões futuras, e exigiam a operação, pois não seria possível adotar sexo oposto ao biologicamente objeto do registro. Podemos citar duas decisões que demonstram essa evolução jurisprudencial, oriundas do Tribunal do Rio Grande do Sul, Apelação Cível no 70064503675/RS, e do Tribunal do Amapá, Apelação no 69300. 
E na terceira fase, atualmente prevalecente, foi aceita a mudança do nome e do sexo independentemente da intervenção cirúrgica, inicialmente em 2017 com o Superior Tribunal de Justiça que acatou o entendimento de que era desnecessária a cirurgia de redesignação de sexo para o pleito de alteração de nome, no Recurso Especial n $1.626 .739 / \mathrm{RS}$, e depois com a decisão do Supremo Tribunal Federal na Ação Direta de Inconstitucionalidade nº 4.275/DF, que se deu interpretação conforme a Constituição ao artigo 58 da Lei de Registros Públicos.

Neste julgamento, assentou-se o entendimento que independentemente de cirurgia de redesignação ou da realização de tratamentos hormonais ou patologizantes, é possível a substituição de prenome e gênero diretamente no ofício do registro civil, resguardando ainda, o sigilo desta alteração nos registros públicos.

Os votos proferidos tem fundamento principiológico constitucional na dignidade da pessoa humana e da igualdade, bem como no direito à saúde, e reconhecem o direito a identidade de gênero como direito humano e da personalidade, citando ainda os Princípios de Yogyakarta sobre a Aplicação da Legislação Internacional de Direitos Humanos em relação à Orientação Sexual e Identidade de Gênero, os quais determinam que ninguém pode ser forçado a se submeter a procedimento cirúrgico ou terapêutico hormonal como requisito para o reconhecimento da identidade de gênero.

Depois de três meses da decisão, em 28 de setembro de 2018, o Conselho Nacional de Justiça, no exercício de sua competência regulamentar dos serviços de notariais e de registros, regulamentou o procedimento administrativo para mudança do registro civil, por meio do Provimento $n^{\circ}$ 73, indo além da decisão do STF ao empregar o termo "transgêneros", que engloba tanto o caso dos transexuais quanto dos intersexuais.

A edição do provimento reflete uma verdadeira política de Estado, no que se refere à alteração do nome e à identidade de gênero, levando em consideração as decisões da Organização Mundial da Saúde de excluir a transexualidade do capítulo de doenças mentais da Classificação Estatística Internacional de Doenças e Problemas Relacionados à Saúde (CID).

Ao dispor sobre a averbação da alteração do prenome e do gênero nos assentos de nascimento e casamento de pessoa transgênero diretamente no Registro Civil das Pessoas Naturais, criou-se um procedimento próprio, de natureza sigilosa, a fim de resguardar tais 
situações, sem a necessidade de se submeter a uma cirurgia de redesignação sexual se não quiserem, podendo agora alterar tanto o gênero, quanto o prenome pela via administrativa.

$\mathrm{O}$ art. $2^{\circ}$ dispõe que toda pessoa, no caso transgênera, maior e plenamente capaz, é facultado o exercício, a qualquer tempo, da opção de promover referidas averbações mediante o cumprimento de certas exigências, a fim de adequar o registro civil à identidade autopercebida, diretamente no ofício onde o assento foi lavrado.

O procedimento tem por fundamento a autonomia da pessoa requerente, autopercebidos como transgêneros, que deverá declarar, perante o registrador civil, a vontade de proceder à adequação da identidade mediante a averbação do prenome, do gênero ou de ambos.

O provimento não trata expressamente da hipótese das mudanças do caso do intersexual ou do transexual não binário, no assento de nascimento bem como sua certidão, para que não conste a especificação de gênero e sim de fazer constar "indefinido", "neutro", "não definido".

Porém, o provimento ao adotar a expressão "transgêneros", diferente da utilizado no julgamento do STF que utiliza o termo "transexualidade", sugere a possibilidade de abarcar alterações do registro civil para tais hipóteses.

\section{Gênero neutro no registro civil das pessoas naturais}

Após a decisão do Supremo Tribunal Federal na Ação Direta de Inconstitucionalidade $n^{\circ} 4.275 / \mathrm{DF}$ e a edição do Provimento $\mathrm{n}^{\circ} 73$ do CNJ, algumas decisões da primeira instância já foram proferidas possibilitando a mudança para gênero neutro no assento registral.

As decisões judiciais permitem a mudança no registro civil de uma pessoa nãobinária tanto do nome quanto do gênero, que poderá passar a constar a expressão "sexo não especificado". Os juízes que reconhecem um terceiro gênero, o neutro, entendem que as pessoas que assim se identificam teriam direito à sua autodeterminação pessoal, autonomia e privacidade, caso não houvesse tal adequação em seu assento de nascimento. 
Em decisão de 21/08/2020, da $1^{\text {a }}$ Vara de Família da Ilha do Governador, da Justiça Estadual do Rio de Janeiro, a possibilidade de adequação do registro para pessoas de gênero neutro, foi reconhecida a partir da analogia com a regra que permite modificar o prenome considerado vexatório, o que se assemelha ao caso julgado, em que se solicitava a modificação da identificação do sexo, para receber tratamento caso não binário.

Já a decisão de 08/04/2021, da Justiça Estadual de Santa Catarina, abordou os vários aspectos que envolvem tal mudança curial no assento de nascimento do cidadão nesses casos. A fundamentação da decisão reconhece que o direito fundamental de autoidentificação do gênero, o que abrange o gênero neutro, não possui suficiente tutela na legislação ordinária, uma vez que o regramento dos registros públicos que impõe o tratamento binário do sexo (art. $54, \S 2^{\circ}$ da Lei $n^{\circ} 6.015$ de 1973).

A segurança jurídica esperada dos registros públicos e sua linguagem no tocante a essa peculiar situação deve facultar a possibilidade de escolha pelo terceiro gênero neutro, nos mesmos moldes da faculdade conferida aos transexuais (PEREIRA, 2019).

O pluralismo epistemológico e a mudança social vivenciada em novos tempos, permitem a autodeterminação da pessoa, como expressão de proteção das minorias. Esta autonomia ou autogoverno da pessoa na contemporaneidade é uma decorrência lógica e racional da concepção de pessoa humana moderna, enquanto ser que se autodetermina, que decide livremente sobre a vida, com vistas ao autodesenvolvimento da personalidade, já possui capacidade de dominar a si e à natureza através da razão (FACHIN, 2007).

Na no dia a dia das serventias, fica a critério dos pais a escolha do sexo, masculino, feminino ou indefinido, na hipótese da Declaração de Nascido Vivo constar a informação de sexo como indefinido, questão até então, não tratada pela lei e pela doutrina registral.

Nestes casos, a necessidade premente do reconhecimento do terceiro sexo é premente, para que essas pessoas possam reconhecer a sua própria sexualidade por escolha, e não por imposição da Medicina ou do Direito (DIAS, 2020).

Os oficiais de registro estão aptos tecnicamente para contribuir com a Justiça na efetivação dos direitos fundamentais do homem, devendo sugerir aos pais que escolham um nome com gênero neutro, compatível ambos os sexos. Assim, a pessoa ao atingir a 
maioridade ou tiver condições de identificar o seu gênero, poderá seguir o mesmo procedimento previsto no Provimento $\mathrm{n}^{\mathrm{o}} 73$ para os transexuais, sem a necessidade de alterar seu prenome (DIAS, 2020).

O princípio da segurança jurídica atualmente, deve ser analisado em conjunto com o da dignidade da pessoa, interação que se expressa na mitigação do princípio da imutabilidade do nome que visava mais a proteção das relações econômicas de terceiros, conforme redação original do artigo 58 da Lei $\mathrm{n}^{\circ} 6.015$ de 1973.

Isso não poderia ser diferente no trato da questão da alteração do nome e gênero do transexual que busca reconhecimento da sua individualidade em seus registros. Neste caso, é essencial a discussão a respeito do confronto entre a segurança jurídica esperada dos registros públicos e o respeito à dignidade e à liberdade do indivíduo.

No entanto, não há uma dicotomia absoluta entre segurança jurídica e justiça material, de forma que nenhum deles é um valor absoluto, dependendo de uma ponderação racional na análise do caso concreto (BRANDELLI, 2014).

Quais serão os efeitos jurídicos com a criação de um terceiro gênero nos registros públicos? Qual o prejuízo social se tal informação de sexo indefinido passar a constar na certidão do cidadão? Os efeitos jurídicos do registro do gênero neutro, criando uma nova classificação no assento registral, englobando as recentes decisões, teriam o condão de alterar a concessão de benefícios previstos legalmente, onde se adota o critério binário? A lei que concede benefícios às mulheres, também, seria extensiva às pessoas classificadas como indefinidas?

Observa-se a concretização dos direitos da personalidade, na função registral como elo de ligação do Estado e o cidadão no amparo das questões existenciais do ser humano. Assim, uma leitura constitucional do direito registral se faz necessária, não como um fim em si mesma, mas como instrumento de efetivação dos princípios da segurança jurídica e da dignidade da pessoa humana.

Um dos fatores que contribuem para a permanente exclusão dessa parcela da população é a dificuldade na mudança de nome e gênero nos documentos de identificação que têm como base o registro de nascimento. O efetivo exercício dos direitos civis pelos 
transexuais e intersexuais no que se refere a alteração do prenome e do gênero é o que se busca analisar no âmbito do registro civil das pessoas naturais, promovendo igualdade e o combate à discriminação.

Essa tendência não diz respeito apenas ao Brasil, e na verdade, já é realidade em outros países. O Tribunal Constitucional Federal Alemão já decidiu que pessoas do chamado terceiro gênero podem ser registradas como intersexuais ou ter a definição de gênero omitida em suas certidões de nascimento, nos autos do processo 1BvR 2019/16, decisão publicada em 08.11.2017. A corte estabeleceu que nova legislação deveria ser criada até 2018 para permitir "designações positivas de gênero" como "intersexual" ou "diverso". Com a nova lei, a Alemanha deve se tornar o primeiro país europeu a permitir o registro de pessoas do terceiro gênero na certidão de nascimento (FRITZ, 2017).

Outros países introduziram o conceito de "sexo neutro" ou "terceiro sexo" nos documentos de identidade, incluindo a Austrália, Canadá, Alemanha, Índia, Nova Zelândia, Paquistão, Tailândia e Grã-Bretanha.

No Brasil, ainda não há legislação específica, mas o Projeto de Lei nº 5255/2016 pretende disciplinar o registro civil do recém-nascido sob o estado de intersexo e aguarda apreciação no plenário da Câmara dos Deputados.

O direito ao reconhecimento da possibilidade de um terceiro gênero, dada a evolução social e jurídica ocorridas, deve alcançar os registros públicos, por meio de medidas de enfrentamento da injustiça cultural, dos preconceitos e dos padrões discriminatórios (PIOVESAN, 2013).

Atenta-se que esta solução só seria válida no campo da intersexualidade, para pessoas transgênero, transexuais não binárias e intersexuais, que poderão incluir sua identidade de gênero nos documentos.

O debate acadêmico a respeito da necessidade de se constar um terceiro gênero necessita de aprofundamentos, bem como o estudo da linguagem adequada dos registros públicos. Afinal, se a própria natureza não definiu de forma binária a pessoa, não caberá aos registros públicos fazê-lo (REAL, 2020). 
A forma segura de garantir a segurança jurídica da natureza dos registros públicos e o respeito a autodeterminação do gênero pelo individuo seria a possibilidade de inserir uma terceira alternativa para o campo do sexo, como a informação "neutro", permitindo que terceiros saibam como aquela pessoa se auto identifica.

O intuito de regulamentar o procedimento de redesignação do nome e gênero pelos transgêneros, acabou por institucionalizar o gênero neutro, contando com o auxílio dos registros públicos na concretude dos direitos humanos em prol desses cidadãos, que não estão na classificação binária de masculino ou feminino nem por natureza, quanto mais formalmente (CASTRO, 2018).

Todo sistema legal que levou em consideração apenas o sexo biológico, bem como, os alcances da identidade de gênero, merecem ser revisados, para se saber da compatibilidade ou não entre ambos no sistema registral brasileiro, a fim de se criar uma nova classificação de gênero nos assentos públicos. Atualmente, o alcance dos direitos fundamentais, especialmente aqueles referentes às minorias, está sendo delimitado pelo Supremo Tribunal Federal, visto que, o debate a respeito do tema, caminha vagarosamente na Câmara dos Deputados.

\section{Considerações finais.}

A identidade do ser humano é formada por vários elementos, sendo o nome e o sexo cruciais na maneira como as pessoas são conhecidas na sociedade, e além disso, o modo como se identificam e querem ser reconhecidas. Portanto, considera-se a identidade de gênero como um dos direitos da personalidade, corolário direto da dignidade da pessoa humana.

A criação de um novo campo de marcador sexual a constar na certidão de nascimento do cidadão reflete a evolução social, aceitação do pluralismo e não discriminação, facultando à pessoa transsexual ou intersexual, a escolha da informação que deverá constar em seu assento, masculino, feminino ou neutro, independente da alteração do nome.

A partir dos conceitos relativos à identidade de gênero, delimitou-se os sujeitos detentores deste direito, notadamente os transsexuais, sem excluir a possibilidade de extensão a outros grupos, como os intersexuais que se identificam como pessoas de gênero neutro.

O Poder Judiciário foi o protagonista no enfrentamento da questão da readequação de nome e gênero, permitindo-a aos transsexuais, mesmo sem a cirurgia de transgenitalização, 
por entender que, a redesignação da identidade de gênero, é um direito que permite à pessoa afetada, o seu pleno desenvolvimento e uma melhor inserção na sociedade.

A aceitação da diversidade é basilar numa sociedade, cujo objetivo, é a plena realização do ser humano. A possibilidade de redesignação da identidade de gênero por via extrajudicial pode contribuir para a diminuição da discriminação e maior aceitação das pessoas afetadas no seio da sociedade.

Desta maneira, os princípios constitucionais de dignidade da pessoa humana, isonomia, liberdade, entre outros, permitiram o STF recepcionar as adequações de identidade de gênero e nome nos livros de registro, de forma a espelhar a realidade social da pessoa afetada.

Diante do exposto no desenvolvimento, do artigo é possível concluir que o Registro Civil das Pessoas Naturais oferece uma via simplificada para que os transexuais e intersexuais possam exercer plenamente a cidadania, alterando de forma célere e efetiva o nome e o gênero nos registros públicos, na efetiva concretização dos direitos fundamentais.

As informações constantes nos assentos registrais têm papel determinante na garantia do exercício efetivo da cidadania de qualquer cidadão, independente de imposições sociais que não refletiam a pluralidade na compreensão de cada ser humano.

Trata-se da aceitação pelo Estado do terceiro gênero, "indefinido", visando a não discriminação em tais hipóteses, a incidência e reconhecimento prático da luta diária e constante das pessoas que nascem nessas condições. Se a natureza não definiu, ou melhor, definiu duplamente, não caberá ao assento registral impor algum rótulo.

O objetivo da alteração do nome e do gênero é facilitar a identificação psíquica da pessoa com aquela constante nos registros públicos, de forma a refletir a realidade da pessoa objeto do assento, com uma terceira via de nomenclatura para a definição do gênero neutro, abarcando hipóteses de mudanças até então não previstas no ordenamento, propiciando a perspectiva de novos estudos.

\section{Referências}


A Gazeta. Juíza de SC dá direito a declaração de gênero neutro em certidão de nascimento. $<$ https://www.agazeta.com.br/brasil/juiza-de-sc-da-direito-a-declaracao-de-genero-neutro-emcertidao-de-nascimento-0421>. Acesso em: 12/04/2021.

ANTONIASSI JUNIOR, Gilmar; FELIPE, Rafael Alves; REIS, Ernane Junior da Silva; FIGUEIREDO, Glória Lúca Alves. Transgeneridade sob o olhar da pessoa trans e as relações familiares. In: BERETTA, Regina Célia de Souza; FIGUEIREDO, Glória Lúca Alves (coord.). (Des)proteções sociais, populações vulneráveis e cidadania. Curitina: Brazil Publising, 2019.

BERKMAN, Ricardo Rabinovich. Sobre o direito à identidade sexual, e aspecto relacionados. In: JUBILUT, Liliana Lyra; BAHIA, Alexandre Gustavo Melo Franco; MAGALHÃES, José Luiz Quadros de. Direito à diferença: aspectos teóricos e conceituais da proteção às minorias e aos grupos vulneráveis. v. 2. São Paulo: Saraiva, 2013.

BRANDELLI, Leonardo. Nome civil da pessoa natural. São Paulo: Saraiva, 2012.

- Segurança jurídica e racionalidade. In: Brandelli, Leonardo (Org.). Estudos de direito civil, internacional privado e comparado: coletânea em homenagem à professora Véra Jacob de Fradera. São Paulo: Liv. e Ed. Universitária de Direito, 2014.

BRASIL. Câmara dos Deputados. Projeto de Lei $n^{o}$ 5.002/2013. Dispõe sobre o direito à identidade de gênero e altera o art. 58 da Lei no 6.015 de 31 de dezembro de 1973. Disponível em: <http:// www.camara.gov.br/sileg/integras/1069623.pdf>. Acesso em: 10/04/2021.

BRASIL. Constituição da República Federativa do Brasil de 1988. Disponível em: $<$ http://www.planalto.gov.br/ccivil_03/constituicao/constituicao.htm>. Acesso em: $10 / 04 / 2021$.

BRASIL. Superior Tribunal de Justiça. REsp 1.626.739/2017-TJRS. Relator: Min. Luis Felipe Salomão. Brasília, DF, 09 de maio de 2017. Disponível em: <https://stj.jusbrasil.com.br/jurisprudencia/484087877/recurso-especial-resp-1626739-rs2016-0245586-9/inteiro-teor-484087902>. Acesso em: 10/04/2021.

BRASIL. Supremo Tribunal Federal. Arguição de Descumprimento de Preceito Fundamental 600. Relator Min. ROBERTO BARROSO. Brasília/DF, 12 dez. 2019. Disponível em: 
<http://www.stf.jus.br/arquivo/cms/noticiaNoticiaStf/anexo/ADPF600.pdf〉. Acesso em 10/04/2021.

BRASIL. Supremo Tribunal Federal. Ação Direta de Inconstitucionalidade 4.275. Relator Min. Marco Aurélio. Brasília/DF, 01 mar. 2018. Disponível em: <http://www.stf.jus.br/arquivo/cms/noticiaNoticiaStf/anexo/ADI4.275VotoEF.pdf>. Acesso em 10/04/2021.

BRASIL. Supremo Tribunal Federal. Recurso Extraordinário 4192182. Relator Min. Dias Toffoli. Brasília/DF, 15 ago. 2018. Disponível em: $<$ https://portal.stf.jus.br/processos/detalhe.asp?incidente=4192182>. Acesso em: $10 / 04 / 2021$.

BRASIL, Senado Federal. PLS $n^{\circ}$ 658, de 2011. Reconhece os direitos à identidade de gênero e à troca de nome e sexo nos documentos de identidade de transexuais. Brasília, DF, 27 out. $2011 . \quad$ Disponível em: $<$ http://www.senado.gov.br/atividade/materia/detalhes.asp?p_cod_mate=103053>. Acesso em: 10/04/2021.

BRASIL. Conselho Nacional de Justiça. Provimento $n^{o} 73$, de 28 de setembro de 2018. Disponível em: <https://atos.cnj.jus.br/files//provimento/provimento_73_28062018_02072018160046.pdf>. Acesso em: 10/04/2021.

BRASIL. Lei $n^{\circ}$. 6.015. Brasília, 31 de dezembro de 1973. Dispõe sobre os registros públicos, e dá outras providências. Disponível <http://www.planalto.gov.br/ccivil_03/leis/16015.htm>. Acesso em: 10/04/2021.

BRASIL. Lei no . 10.406. Brasília, 10 de janeiro de 2002. Institui o Código Civil. Disponível em: <http://www.planalto.gov.br/ccivil_03/leis/2002/L10406.htm>. Acesso em: 10/04/2021.

BRASIL. Lei $n^{\circ}$. 12.662. Brasília, 5 de junho de 2.012. Assegura a validade nacional da Declaração de Nascido Vivo. Disponível <http://www.planalto.gov.br/ccivil_03/_Ato2011-2014/2012/Lei/L12662.htm>. Acesso em: $10 / 04 / 2021$. 
BUCAR, Daniel; TEIXEIRA. Daniele Chaves. Autonomia e Solidariedade. In: TEPEDINO, Gustavo; TEIXEIRA, Ana Carolina Brochado; ALMEIDA, Vitor (coord). O Direito Civil entre o sujeito e a pessoa: estudos em homenagem ao professor Stefano Rodotà. Belo Horizonte: Fórum, 2016.

CARDIN, Valéria Silva Galdino Cardin; CAZELATTO, Caio Eduardo Costa. Da vulnerabilidade social das minorias sexuais sob a perspectiva jurídica. In: CAMPOS, Nilson Tadeu Reis Campos (org.). O Direito e as pessoas vulneráveis na contemporaneidade. Rio de Janeiro: Lumen Juris, 2016.

CASTRO, Rafael Spinola. Reflexões jurídicas acerca do novo tratamento registral da pessoa transgênero. In: Del Guércio Neto, Arthur; Del Guércio, Lucas Barreli (coord.). O Direito Notarial e Registral em artigo Vol. III. São Paulo: YK Editora, 2018.

CONSELHO FEDERAL DE MEDICINA. Resolução nº 1.955, de 03 de setembro de 2010. Dispõe sobre a cirurgia de transgenitalismo e revoga a Resolução CFM no 1.652/2002. Diário Oficial da União, Poder Executivo, Brasília, n. 232, 2 dez. 2002. Seção 1, p.80/81

CUNHA, Leandro Reinaldo da. Identidade e redesignação de gênero: aspectos da personalidade, da família e da responsabilidade civil. Rio de Janeiro: Lumen Juris, 2.015.

DIAS, Maria Berenice. Homoafetividade e os direitos LGBTI. 6 ed. reformulada. São Paulo: Editora Revista dos Tribunais. 2.014.

. Manual do Direito das Famílias. 13. ed. rev. ampl. e atual. Salvador: Editora Editora JusPodivm, 2020.

DINIZ, Maria Helena. O estado atual do biodireito. 3. ed. São Paulo: Saraiva, 2006.

FACHIN, Luiz Edson. Fundamentos, limites e transmissibilidade: anotações para uma leitura crítica, construtiva e de índole constitucional da disciplina dos direitos da personalidade no Código Civil brasileiro. In: CORRÊA, Elídia Aparecida de Andrade (coord.); GIACOIA, Gilberto (coord.); CONRADO, Marcelo (coord.). Biodireito e dignidade da pessoa humana. Diálogo entre a ciência e o direito. $1^{\circ}$ ed. $2^{\circ}$ tir. Curitiba: Juruá, 2.007.

FOUCAULT, M. Herculine Barbin: o diário de um hermafrodita. Tradução de Irley Franco. Rio de Janeiro: Francisco Alves, 1982. 
FRITZ, Karina Nunes. Tribunal Constitucional Alemão admite a existência de um terceiro gênero (comentário e tradução). Civilistica.com. Rio de Janeiro, a. 6, n. 2, 2017. Disponível em: <https://civilistica.com/wp-content/uploads1/2017/12/Fritz-civilistica.coma.6.n.2.2017-2.pdf >. Data de acesso: 10/04/2021.

GONÇALVES, Tamara Amoroso; CHAMBOULEYRON, Ingrid Cyfer. A livre orientação sexual como direito à diversidade e a não discriminação. In: FACHIN, Melina Girardi; IKASA, Daniela; PIOVESAN, Flávia. Direitos humanos na ordem contemporânea: proteção nacional, regional e global. Curitiba: Juruá, 2010.

IBDFAM. Justiça autoriza inscrição de "sexo não especificado" em registro de pessoa nãobinária. Disponível em: <https://ibdfam.org.br/index.php/noticias/7756/Justi\%c3\%a7a+autoriza+inscri\%c3\%a7\%c3\% a3o+de+\%22sexo+n\%c3\%a3o+especificado $\% 22+e m+$ registro+de+pessoa+n\%c3\%a3obin\%c3\%a1ria\%22>. Acesso em: 10/04/2021.

LACERDA, Dennis Otte. Direitos da personalidade na contemporaneidade: a repactuação semântica. Porto Alegre: Sergio Antonio Fabris Ed., 2010.

LIMA, L.F. A "VERDADE" PRODUZIDA NOS AUTOS: uma análise de decisões judiciais sobre retificação de registro civil de pessoas transexuais em Tribunais brasileiros. 185f. 2015 Dissertação (Mestrado em Antropologia social) - Departamento de Antropologia, da Faculdade de Filosofia, Letras e Ciências Humanas, Universidade de SãoPaulo, 2015.

OMS, ORGANIZAÇÃO MUNDIAL DA SAÚDE. Classificação Internacional de Doenças (CID 11). Disponível em: $<$ https://www.paho.org/bra/index.php?option=com_content\&view=article\&id=5702:omsdivulga-nova-classificacao-internacional-de-doencas-cid-11\&Itemid=875->. Acesso em: $10 / 04 / 2021$.

PEREIRA, Gustavo Faria. Mudança de prenome por força do provimento n. 73 do Conselho Nacional de Justiça (CNJ) e o registro de imóveis - privacidade decorrente dos direitos de personalidade x publicidade do direito registral imobiliário. In: FERRO JÚNIOR, Izaías 
Gomes; SCHWARZER, Márcia Rosália (coord.). Registro civil das pessoas naturais. Salvador: Editora JusPodivm, 2019. Salvador: Editora JusPodivm, 2019.

PIOVESAN, Flávia. Igualdade, diferença e direitos humanos. In: JUBILUT, Liliana Lyra; BAHIA, Alexandre Gustavo Melo Franco; MAGALHÃES, José Luiz Quadros de. Direito à diferença: aspectos teóricos e conceituais da proteção às minorias e aos grupos vulneráveis. v. 1. São Paulo: Saraiva, 2013.

PRINCÍPIOS DE YOGYAKARTA. Princípios sobre a aplicação da legislação internacional dedireitos humanos em relação à orientação sexual e identidade de gênero. Disponível em: <http://www.clam.org.br/uploads/conteudo/principios_de_yogyakarta.pdf Acesso em: $10 / 04 / 2021$.

REAL, Gustavo Câmara. Viabilidade do ensino sobre diversidade de gênero nas escolas brasileiras. In: MENEZES, Joyceane Bezerra de Menezes; TEIXEIRA, Ana Carolina Brochado Teixeira (coord.). Gênero, vulnerabilidade e autonomia: repercussões jurídicas. Indaiatuba, SP: Editora Foco, 2020.

SUTTER, Matilde Josefina. Determinação e mudança de sexo - aspectos médico-legais. São Paulo: Editora Revista dos Tribunais, 1.993.

VIEIRA, Tereza Rodrigues. A bioética e o direito à adequação de sexo do transexual. In: VIEIRA. Tereza Rodrigues (coord.). Bioética e sexualidade. São Paulo: Editora Jurídica Brasileira, 2.004. 